\title{
The Effect of Loss of Stability of an Arc-Plate Made of Ti-Ni Shape Memory Alloy
}

\author{
A.B. Bondarev ${ }^{1}$, M.A. Khusainov ${ }^{2}$, V.A. Andreev ${ }^{\mathrm{a}}$ \\ ${ }^{1}$ Industrial Centre MATEKS Ltd, Moscow, Russia \\ ${ }^{2}$ Yaroslav the Wise Novgorod State University, Velikiy Novgorod, Russia
}

\begin{abstract}
Mechanical behavior of an arched Ti-Ni strip with shape memory effect is investigated. It is shown that an arched Ti-Ni strip bent inversely to its initial shape at heating restores its initial shape with a snap ("the snap effect"). This type of behavior is caused by loss of stability at reverse martensitic transformation. It should be noted that the clap is heard when the strip's ends rest on the stationary hinged grips. If one or both ends are free, the transition to the austenitic state and the form changing process occur steadily. Shift of one of the edges of an arched strip at phase transformation is a necessary condition for loss of stability with a realization of a snap with a clap. Regular patterns and peculiarities of form changing of an arched strip at different displacement values are found out.
\end{abstract}

\section{Introduction}

Much consideration has been given to the problem of stability of rectangular plates and bars supported (clamped) on the edges in the limits of Hooke's law and beyond the limits of elasticity [1]. However, insufficient attention has been paid to a question of stability of convex plates made of Ti-Ni alloy with shape memory effect (SMA). These objects can serve as active temperature-sensitive and thermal force elements in temperature actuated switches, in isolation valves, in fire systems, and other devices. Buckling of an arched Ti-Ni strip at heating is accompanied by development of reactive and axial forces, causing recovery of the initial shape. It was shown in [2, 3] that form changing of an arc is unstable in case of hinge support. Transition from stable to unstable state of an arched strip occurs abruptly (with a clap), the same process is observed on spherical segments [4]. Kinetics of reactive forces in the material of the se objects, caused by a loss of stability, is quite similar. The difference is that an arched strip snaps back only in case of a hinge support. Displacement along the longitudinal axis is always required. Whereas spherical segments fixed along the edges do not snap back. In [5] based on experimental data analysis of stability of behavior of an arched strip is given, where with the theory of diffused martensitic transitions the conditions under which the form changing process becomes unstable were singled out.

\section{Experimental and Discussion}

The TiNi plates after cold rolling with intermediate annealing at $600^{\circ} \mathrm{C}$ for 5,0 min to $\varepsilon_{\Sigma} \approx 35-40 \%$ were used for studying mechanical behavior of the arched strip in regard to loss of stability. They were then annealed in a fixed state at $500^{\circ} \mathrm{C}$ for $30 \mathrm{~min}$. As a result of such a treatment the temperatures of martensitic transformations were the following:

$$
\mathrm{M}_{\mathrm{s}}=18^{\circ} \mathrm{C} ; \mathrm{M}_{\mathrm{f}}=6^{\circ} \mathrm{C} ; \mathrm{A}_{\mathrm{s}}=28^{\circ} \mathrm{C} ; \mathrm{A}_{\mathrm{f}}=42^{\circ} \mathrm{C} \text { for } \mathrm{Ti}-50,3 \text { at } \% \mathrm{Ni} \text {. }
$$

aemail: Olga.Makarova@novsu.ru

This is an Open Access article distributed under the terms of the Creative Commons Attribution-Noncommercial License (http://creativecommons.org/licenses/by-nc/3.0/), which permits unrestricted use, distribution, and reproduction in any noncommercial medium, provided the original work is properly cited. 


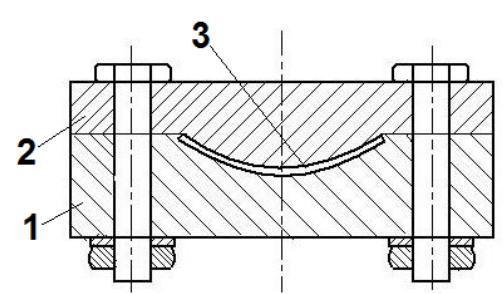

Fig.1. A press mould for shape-setting. 1 a former block; 2 - a punch; 3 - an arched strip

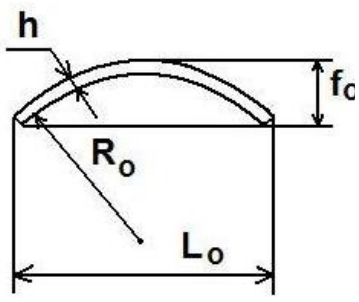

Fig.2. An arched strip

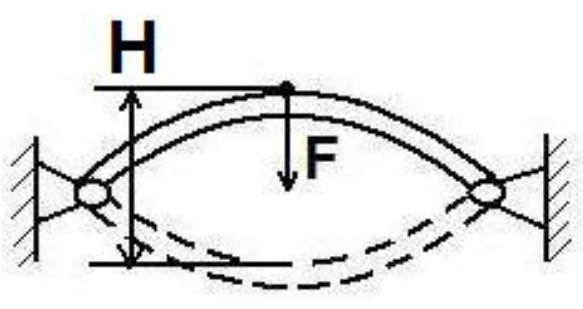

Fig.3. An arched strip bent in martensite

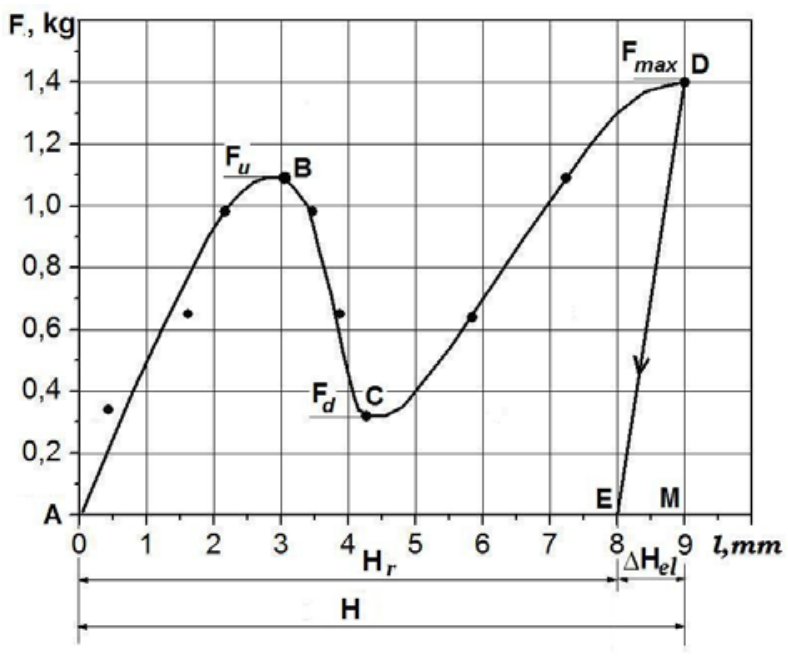

Fig.4. The diagrams of an arched strip bent inversely to its initial shape $(\mathrm{ABCD})$ and unloading $\mathrm{DE}$ in martensite, where $\Delta H_{e l}$ - elastic component of full-scale deflection; $H_{\mathrm{r}}$ recovering component of full-scale deflection
Afterwards the plates with dimensions $l \times b \times h=(20 \div 35) \times(6 \div 10) \times(0,4 \div 0,5) \mathrm{mm}$ were bent in a press mould (in martensitic state) with a given radius $\mathrm{R}_{0}$ (Fig.1) at a maximum bending deflection $f=\mathrm{R}_{0}\left[1-\overline{\left.1-L_{0} / R_{0}\right)^{2}}\right.$, where $L_{0}=R_{0} \sin \left(l / R_{0}\right)$ is half the chord between the ends of the bent strip. Further the fixed strip was annealed at $420 \mathrm{C}, 1,5 \mathrm{~h}$ in order to set the shape. These procedures were aimed at improving the reversibility of the martensitic transformations (MT). Next, the arched strip (Fig.2) was placed into a deforming machine with hinged supports (Fig. 3) and bent with force F in martensitic state inversely to the initial outline. The full-scale deflection value of the arched strip (H) was $H=2 f_{0}-h$, where $f_{0}$-initial bending deflection $(9 \mathrm{~mm})$. Fig. 4 shows the diagram of the bend of the arched strip as with the spherical segment [4] and presents a characteristic dependency between force $F$ and bending parameter $\mathrm{H}$. It is seen that the bending force of the arch to the centre of the curvature increases up to the upper critical value $\mathrm{P}_{\mathrm{u}}$, after which the arch gives a clap (snap) from equilibrium position $\mathrm{B}$ to position $\mathrm{C}$. After that the bending force increases again, reaching $\mathrm{F}_{\max }$ at a full-scale deflection value $(H-h)$. The removal of the applied force results in minor decrease in $H$ as a consequence of elastic strain display. If now, having removed the force F, one heats the strip, it snaps back with a clap to the initial shape (Fig.5). However, the snap effect is observed when the ends of the arched strip are supported by hinges. When heated, straightening of the strip occurs because of generation of the reactive force $\mathrm{Q}_{\mathrm{r}}$, developing in the material. At the same time compressive forces $P$ are developing at the ends of the strip, causing extra bend of the strip and loss of stability of the system. As a result the arched Ti-Ni strip either snaps with a clap or does not go through the middle plane. The snap effect in this case is not realized. To eliminate such type of behavior of the strip at heating, one should give some displacement of one of the ends of the strip (Fig. 6). It helps change the gap width $\mathrm{Z}$ in order to control value of constraint (fixed-end stiffness).

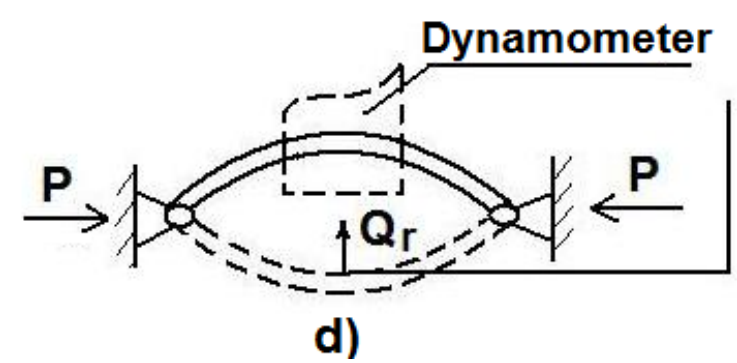

Fig.5. The arched strip after heating with a stroke against the obstacle

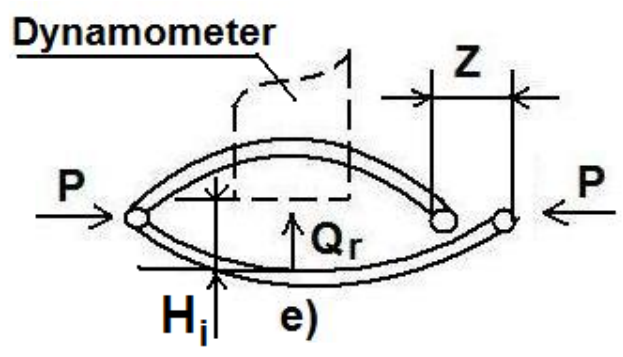

Fig.6. An arched strip with a probability of displacement $\mathrm{Z}$ at heating 


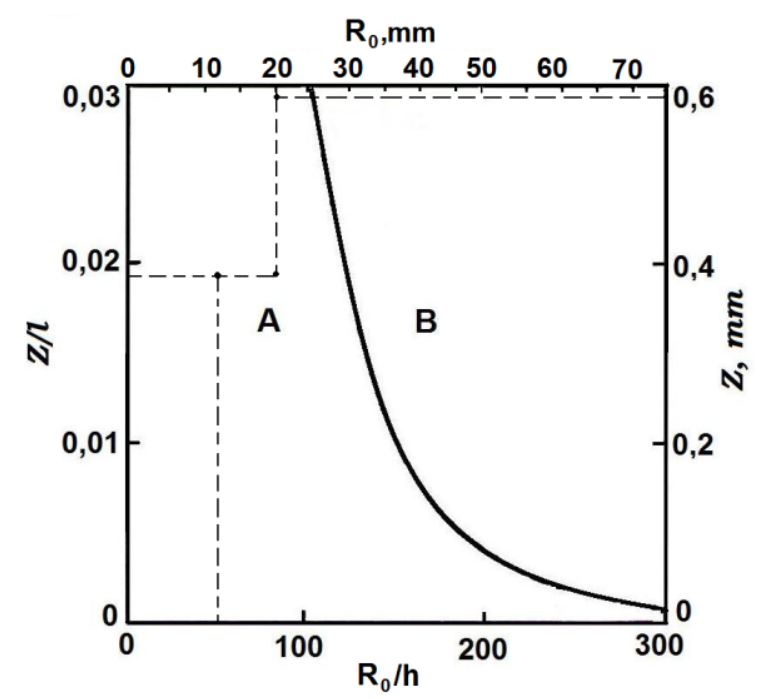

Fig.7. The critical gap width $\mathrm{Z}$ to reveal the snap effect vs. the radius of initial bend of the arched strip $R_{0}$.

A - the domain of unstable form changing (shape recovery with a snap); B - stable form changing (typical shape memory effect)
It is shown by an experiment that at constrained form changing the process of snapping-back is dynamic. If one sets an obstacle (dynamometer) on the way of shape recovery then at heating a stroke is realized, the value of which depends on the distance between the strip and the obstacle (Fig.6). Analysis of data received shows full matching for mechanical behavior of arched strip and spherical segment [6].It is testified by complete identity of the diagrams of deforming in martensite and domains of loss of stability and realization of high force parameters $\left(\mathrm{P}_{\text {imp }}, \mathrm{P}_{\mathrm{r}}\right)$ at optimum geometry of the objects under investigation. One of the main parameters reflecting probability of the snap effect of the arched strip is displacement value of an end of the strip at heating. According to [5], the changed arched strips become unstable, i.e. the snap effect is realized with a gap $\mathrm{Z}<\mathrm{Z}_{\text {c.v. }}$, where $\mathrm{Z}_{\text {c.v. }}$ is a critical value of the gap, above which the effect is suppressed. In other words, form changing occurs steadily without any snaps. Fig. 7 demonstrates how critical gap varies with the initial radius of curvature $\mathrm{R}_{0}$ of the strip in the dimensionless coordinates $\left(Z_{c . v .} / l\right)-\left(R_{0} / h\right)$ and at constant value $l / h=40$.

The arched strip with the parameters $l \times b \times h=$ $31 \times 11 \times 0,4 \mathrm{~mm}, \mathrm{R}_{0}=20 \mathrm{~mm}, R_{0} / h=51 \mathrm{~mm}$ at $\mathrm{Z}=0,58 \mathrm{~mm}$ fits well in the domain of unstable form changing. The diagram (Fig.7) can be used for identification of the dimensions of the arched strip for practical purposes.

Force parameters of the arched strip were measured by means of the device, represented in Fig. 7 after bending in martensite. The rod, connected with the dynamometer, was set successively in positions $1 ; 2 ; 3 ; 4 ; 5$; 6. Next the strip was heated to $\mathrm{A}_{\mathrm{f}}+15^{\circ} \mathrm{C}$. The forces developing by the arched strip were registered on the dynamometer's dial. Control measurements were done on the tensile machine FPZ 1/10 (Germany) with a diagram bend in martensite with heating to austenite.

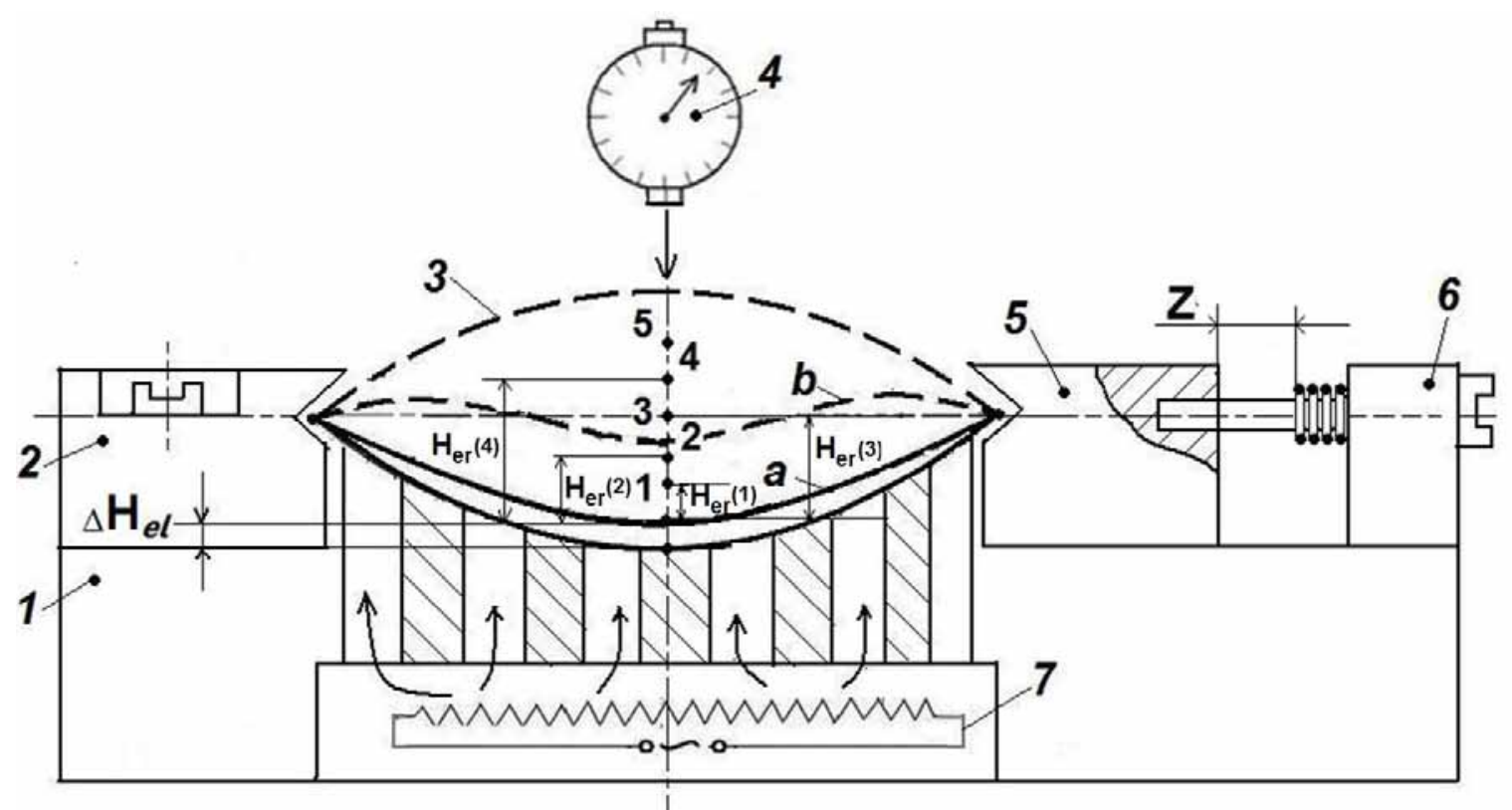

Fig.8. The device for measuring of force parameters of an arched strip, alloy Ti- 50,3 aT\%Ni. 1- body; 2,6 - immovable supports; 3 -arched strip; ; 4 - dynamometer; 5- movable support; 7 - heater. a - an arched strip after bending; b - a typical form of the arched strip at the point of losing stability at heating 
It is shown by experiments that in the positions $1 ; 2 ; 3$ the deformation jump is not realized. Only reactive forces appear, since in the positions the arched strip is hardened by aging in compressed condition. In position 4 the arched strip snaps back with a clap and maximum impact force. Next, in positions 5 impact force dies out, reactive forces drop to zero. It is shown that an arched $\mathrm{Ti}-\mathrm{Ni}$ strip with a hinged movable support of the end at heating always loses its stability and snaps back with a clap to initial shape. Displacement value $(Z)$ of the movable support is small at $\mathrm{R}_{0} \leq 20 \mathrm{~mm}, \mathrm{Z}$ no more $0,5 \div 0,7 \mathrm{~mm}$. According to estimated data [5] with the increase in $R_{0}>50 \mathrm{~mm}\left(\mathrm{R}_{0 / \mathrm{h}}>200\right)$ the gap width $(Z)$ decreases to $0,02 \mathrm{~mm}$. At these parameters the snap effect disappears.

Below the results of measuring of force parameters of the arched Ti-Ni strip (first bent in martensite) at heating are presented. The research was conducted on the arched Ti-Ni strip with the following dimensions $\mathrm{L}_{0}=31 \mathrm{~mm}, \mathrm{R}_{0}=20 \mathrm{~mm}$,

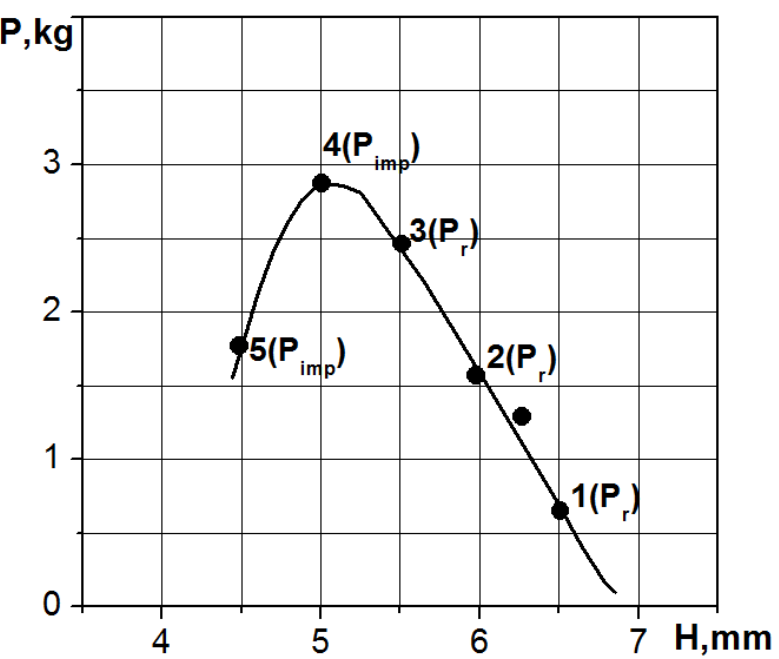

Fig. 9. Force parameters of the arched strip vs. value of the easy running at heating. Points on the chart indicate the position of the obstacles $\mathrm{h}=0,4 \mathrm{~mm}$ and $\mathrm{f}_{0}=4,5 \mathrm{~mm}$, at $\mathrm{Z}=0,58 \mathrm{~mm}$. Fig. 9 plots generating forces vs. value of easy running at heating of the arched strip. It is seen that the impact force on the dynamometer and reactive forces at the point of loss of stability of the arched Ti-Ni strip increase with the growth of easy running $\left(H_{\mathrm{er}}\right)$ (see Fig. 8), reaching its peak value $H_{\mathrm{er}}=5,5 \mathrm{~mm}$, with subsequent sharp decline accompanied by full shape recovery. Axial forces at that reach $1,3 \mathrm{~kg}$.

\section{Conclusions}

1. Method of investigation of the deformed system in the form of an arched strip made of Ti-Ni shape memory alloys was worked out.

2. Mechanical behavior of the arched strip was studied both theoretically and experimentally in the cycles bend in martensite $\leftrightarrow$ heat to austenite. It is shown that force parameters of the arched strip at $\mathrm{R}<50 \mathrm{~mm}$, $\mathrm{R} / \mathrm{h}<200$ realize only in the constrained condition, at some displacement $(\mathrm{Z})$ of the movable support. It is shown that the arched strips with $\mathrm{R}>50 \mathrm{~mm} \mathrm{R} / \mathrm{h}>200 \mathrm{~mm}$ do not snap back. Under these conditions the critical gap width $(Z)$ becomes less than $0,02 \mathrm{~mm}$.

3. A developed model in [5] agrees with the results of the experiment, and it can be used for designing thermo-devices of different applications.

\section{References}

[1] A.S. Vol'mir, Stability of Deformed Systems [in Russian], Moscow (1967).

[2] M.A. Khusainov, Stability and mechanical behavior of an arched strip made of a shape memory alloy [in Russian]. Novgorod, Volime 10 (1998).

[3] Khusainov M.A., Malukhina O.A., Belykov V.N., Letenkov O.V. Investigation of Resistance of Alloy Spherical Sheaths with Shape Memory Effect (SME) // Proceedings of the Second International Conference on Shape Memory and Superelastic Technologies (SMST-97). USA, California, Alisomar Conference Centre Pacific Grove. 206 March 1997. P. 215 -219

[4] A.B. Bondarev, M.A. Khusainov, M.V. Chukhonkin, O.V. Letenkov, V.A.Andreev. Force parameters of spherical segments made of TiNi alloy with a shape memory effect [in Russian]. Vestnik NovGU. Volume 50 (2009).

[5] G.A. Malygin, M.A. Khusainov, Stability of the mechanical behavior of an arched TiNi strip under the conditions of the constrained shape memory effect. SPb., Technical Physics. Volume 74, Is. 10 (2004).

[6] M.A.Khusainov, A.B. Bondarev, V.A. Andreev Character features of spherical segments fracture from shape memory alloy // Proceedings of the International Conference on Shape Memory and Superelastic Technologies (SMST-07). Editor Shuichui Miyazaki. Japan, Tsukuba. December, 2007. P. 247-255. 